\title{
PENGARUH BIMBINGAN KLASIKAL BERBANTUAN MEDIA VIDEO UNTUK MENINGKATKAN MOTIVASI BELAJAR SISWA DI SMP NEGERI 2 KIKIM SELATAN
}

\author{
Bogi Wulansyah \\ SMP NEGERI 2 KIKIM SELATAN \\ Email: bogiaja05@gmail.com
}

\begin{abstract}
ABSTRAK
Penelitian ini bertujuan untuk mengetahui pengaruh bimbingan klasikal berbantuan media video untuk meningkatkan motivasi belajar siswa di SMP Negeri 2 Kikim Selatan. Metode dalam penelitian ini adalah eksperimen pretest-posttest design group. Populasi penelitian ini berjumlah siswa 60 orang, sedangkan sampel diambil sama dengan jumlah populasi. Data diperoleh menggunakan teknik angket. Selanjutnya data yang diperoleh dianalisis menggunakan statistika uji-t. Hasil penelitian menyimpulkan bahwa layanan bimbingan klasikal berbantuan media video dapat meningkatkan motivasi belajar siswa di SMP Negeri 2 Kikim Selatan. Hal ini dibuktikan dari hasil pengujian hipotesis dimana thitung $=12,15>t_{\text {tabel }}=1,67$ yang berarti tolak $\mathrm{H}_{0}$ dan terima $\mathrm{H}_{a}$.

Kata Kunci: Bimbingan Klasikal, Media Video, Motivasi Belajar

\section{CLASSIFY TUTORIAL IMPACT WITH VIDEO MEDIA TO INCREASE THE STUDENT'S LEARNING MOTIVATION AT 2 SOUTH KIKIM JUNIOR} HIGH SCHOOL
\end{abstract}

\begin{abstract}
The study was made to advance classification of the impact that led to a media review to advance student studies at South Kikim junior high school. The method in this study is a precursor posttest design group experiment. The study's population numbered 60 students, while the sample was taken to equal population. Data obtained using an angket technique. The data obtained is analysis using a statistika uji-t. The study concluded that a classified media assistance service could promote the study of students at South Kikim junior high school. This is verified by the results of hypothetical testing where thitung $=12,15>$ ttable $=1.67$ which means deny h0 and accept ha.
\end{abstract}

Keywords: Classified Guidance, Video Media, Learning Motivation 


\section{PENDAHULUAN}

Era globalisasi perkembangan ilmu pengetahuan dan teknologi pun semakin mendorong upaya-upaya pembaharuan dalam pemanfaatan hasil-hasil teknologi dalam proses belajar. Sesuai dengan visi dari Undang-undang Republik Indonesia (UURI) No. 20 tahun 2003 tentang Sisdiknas adalah : "Untuk mewujudkan sistem pendidikan sebagai pranata sosial yang kuat dan berwibawa untuk memberdayakan semua warga negara Indonesia yang berkualitas, sehingga mampu dan proaktif menjawab tantangan zaman yang selalu berubah".

Berdasarkan observasi dan wawancara dengan guru bimbingan dan konseling di SMP N 2 Kikim Selatan Kabupaten Lahat, diperoleh data dari guru bimbingan dan konseling bahwa siswa kelas VIII SMP N 2 Kikim Selatan Kabupaten Lahat mempunyai masalah motivasi belajar yang kurang, hal ini di sebabkan oleh beberapa faktor antara lain: Fasilitas belajar yang masih kurang lengkap disekolah 30\%, nilai hasil belajar rata-rat 60, masih rendahnya presentase untuk melanjutkan ke sekolah yang lebih tinggi sebesar 25\% sehingga siswa tidak mempunyai motivasi untuk belajar lebih giat lagi, kesadaran orang tua akan pentingnya pendidikan bagi anak-anaknya sebesar 30\%, letak/ lokasi sekolah yang jauh dari jalan atau lokasi yang masuk ke dalam desa berjarak sekitar $4 \mathrm{~km}$, sehingga menyebabkan tidak banyak siswa yang mau sekolah di SMP Negeri 2 Kikim Selatan Kabupaten Lahat.

Upaya yang dilakukan oleh pihak sekolah di SMP Negeri 2 Kikim Selatan Kabupaten Lahat melalui peran guru bimbingan dan konseling dalam membantu sisiwa untuk meningkatkan minat dan prestasi belajar siswa, kebanyakan hanya dengan menggunakan layanan konseling individual. Upaya tersebut kurang mendapat hasil optimal, karena layanan konseling individual itu dilakukan secara perseorangan sehingga tidak efektif diberikan kepada siswa yang jumlahnya cukup banyak dan waktu yang dimiliki guru bimbingan konseling yang terbatas, maka dilakukanlah bimbingan klasikal.

Bimbingan klasikal terjadi interaksi antara siswa dengan guru bimbingan dan konseling/ konselor. Dimana guru pembimbing/konselor sebagai sumber informasi 
memiliki kebutuhan untuk menyampaikan informasi (bahan ajar) kepada siswa sebagai penerima informasi.

Maka dari itu guru bimbingan dan konseling sekurang - kurangnya guru harus dapat memilih dan menggunakan media secara tepat untuk memberikan bimbingan, salah satunya dengan menggunakan media video. Media video mempunyai banyak manfaat sangat membantu dalam memberikan informasi kepada siswa, dapat membantu peserta didik dalam memahami sebuah materi atau ilmu, Peserta didik akan lebih berkonsentrasi dan berdampak pada pemahaman peserta didik itu sendiri karena alat pendengaran dan penglihatan digunakan secara bersamaan sehingga membutuhkan konsentrasi yang besar. Selain hal tersebut, waktu yang dibutuhkan saat memberikan bahan ajar pun akan lebih efisien dan dapat menjadikan pendidik yang inovatif dan kreatif karena dapat berkreasi dengan media tersebut.

Menurut Badarudin (2015) motivasi belajar adalah dorongan energi atau psikologis siswa yang melakukan suatu tindakan agar menguasi sesuatu yang baru berupa pengetahuan, keterampilan, kemauan, kebiasaan dan sikap. Apabila siswa memahami tujuan belajar, kemungkinan besar siswa akan termotivasi belajar yang dapat diukur dengan aspek-aspek motivasi belajar siswa.

\section{LANDASAN TEORI}

Pada dasarnya motivasi adalah suatu usaha yang disadari untuk menggerakkan, menggarahkan dan menjaga tingkah laku seseorang agar ia terdorong untuk bertindak melakukan sesuatu sehingga mencapai hasil atau tujuan tertentu. Menurut Sudarwan (dalam Suprihatin, 2015) Motivasi diartikan sebagai kekuatan atau dorongan, kebutuhan, semangat, tekanan, atau mekanisme psikologis yang mendorong seseorang atau sekelompok orang untuk mencapai prestasi tertentu sesuai dengan apa yang dikehendakinya.

Dapat peneliti simpulkan bahwa motivasi belajar adalah dorongan energi atau psikologis siswa yang melakukan suatu tindakan agar menguasai sesuatu yang baru berupa pengetahuan, keterampilan, kemampuan, kemauan, kebiasaan dan 
sikap. Apabila siswa memahami tujuan belajar, kemungkinan siswa akan termotivasi belajar yang dapat diukur dengan aspek-aspek motivasi belajar siswa.

Pengertian layanan bimbingan klasikal Direktorat Jendral Guru dan Tenaga Kependidikan Kementrian Pendidikan dan kebudayaan (2006:55) mengemukakan pendapat : Layanan bimbingan klasikal merupakan salah satu macam kegiatan layanan bimbingan dan konseling yang melayani sejumlah peserta didik dalam satuan kelas satu rombongan belajar dan dilaksanakan di kelas dalam bentuk tatap muka antara guru bimbingan dan konseling dengan peserta didik atau konseli.

Sementara menurut Menurut Geltner dan Clark (dalam Mukhtar, Yusuf, dan Budiamin, 2016) bimbingan klasikal adalah layanan yang bersifat preventive, curative, preservative, dan developmental merupakan cara yang efisien dalam memberikan informasi kepada siswa sejumlah satuan kelas.

Dilihat dari uraian diatas peneliti dapat menyimpulkan bahwa bimbingan klasikal adalah layanan Bimbingan dan Konseling yang diberikan kepada peserta didik oleh guru Bimbingan dan Konseling (Guru BK) atau Konselor kepada sejumlah peserta didik dalam satuan kelas yang dilaksanakan di dalam kelas untuk memfasilitasi siswa untuk mencapai perkembangan diri secara maksimal.

Menurut Tohirin (2007: 150) bimbingan klasikal layanan informasi bidang sosial diberikan secara klasikal. Langkah-langkah pelaksanaan bimbingan klasikal yaitu:

a. Pendahuluan. Sebelum melakukan bimbingan klasikal guru pembimbing harus bisa mengenali suasana terlebih dahulu. Agar nantinya bimbingan klasikal dapat berjalan dengan baik, maka penelitibisa mencairkan suasana dengan menyapa siswa terlebih dahulu, mengadakan apresiasi dan pre-test

b. Inti dalam kegiatan bimbingan klasikal guru pembimbing menjelaskan materi yang diberikan kepada siswa secara rinci, guru pembimbing dituntut untuk memahami dan menguasai keterampilan-keterampilan dalam pemberian layanan klasikal, diantaranya keterampilan bertanya, memberikan penguatan, keterampilan memberikan variasi, keterampilan menjelaskan dan keterampilan mengelola kelas 
c. Penutup. Sebelum kegiatan bimbingan klasikal diakhiri, peneliti mengadakan tanya jawab kepada siswa untuk mengetahui sejauh mana siswa memperhatikan materi yang disampaikan, menyimpulkan materi yang telah dibahas itu sangat perlu untuk mengetahuisejauh mana respon dari siswa. Setelah itu evaluasi kegiatan lanjutan,dan terakhir menutup bimbingan dengan salam

Menurut Munir (2012:348) Video adalah teknologi penangkapan, perekaman, pengolahan, dan penyimpanan, pemindahan, dan perekonstruksian urutan gambar diam dengan menyajikan adegan-adegan dalam gerak secara elektronik. Video merupakan gambar yang bergerak. Jika objek pada animasi adalah buatan, maka objek pada video adalah nyata.

Kerangka koseptual dalam penelitian ini dapat dilihat pada diagram berikut.

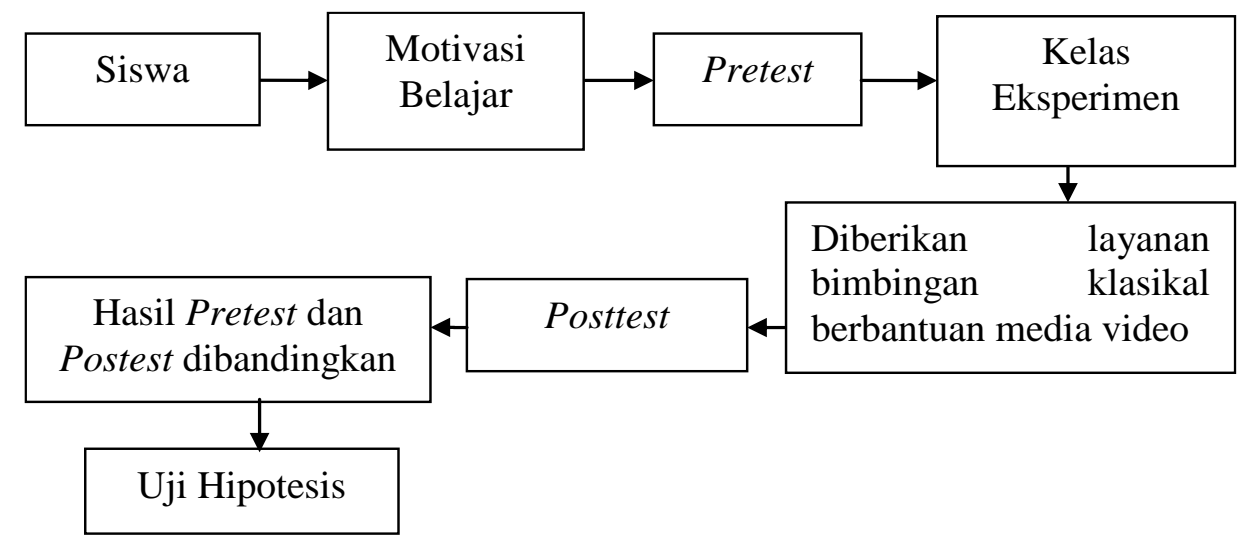

\section{Gambar 1. Kerangka Berpikir}

\section{HASIL PENELITIAN DAN PEMBAHASAN}

\section{A. Hasil Penelitian}

\section{Hasil Penelitian Data Pretest dan Posttest}

Data yang diperoleh dari hasil jawaban angket pretest dan posttest yang berjumlah 25 butir pada 60 peserta didik kelas VIII SMP Negeri 2 Kikim Selatan tahun pelajaran 2018/2019. Data pretest diperoleh skor terkecil 69, skor terbesar 92 dengan rentang 23. Untuk lebih jelasnya data pretest juga bisa dilihat pada histogram ini. 


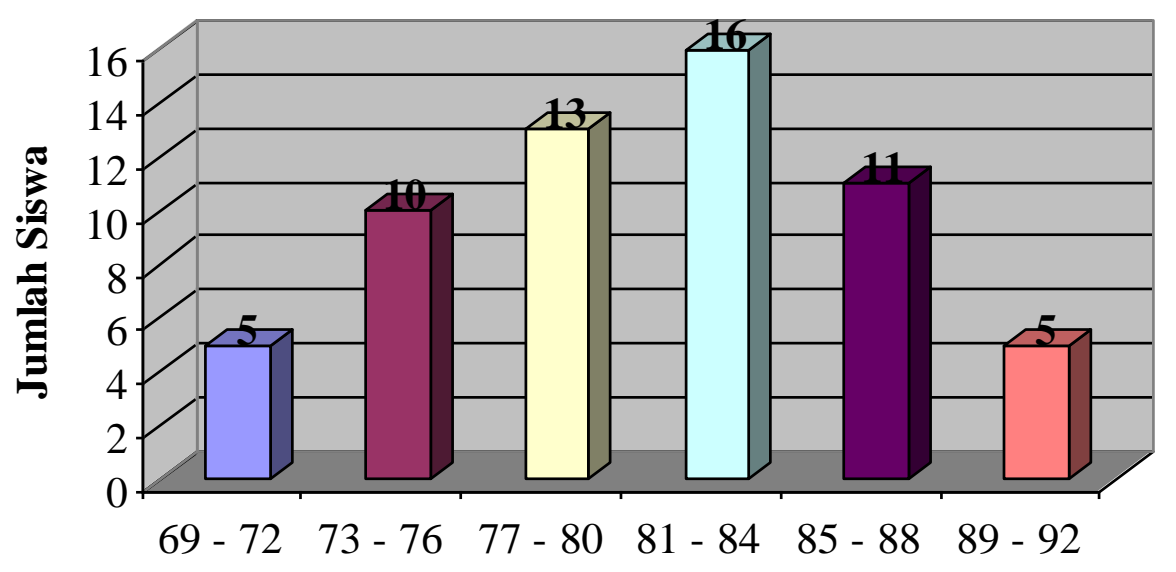

Interval Skor

Gambar 2. Histogram Data Pretest

Skor data posttest dari 60 siswa terhadap 25 butir angket diperoleh skor terkecil 81, skor terbesar 102 , dan rentang atau selisihnya 21 . Untuk lebih jelasnya data posttest juga bisa dilihat pada histogram ini

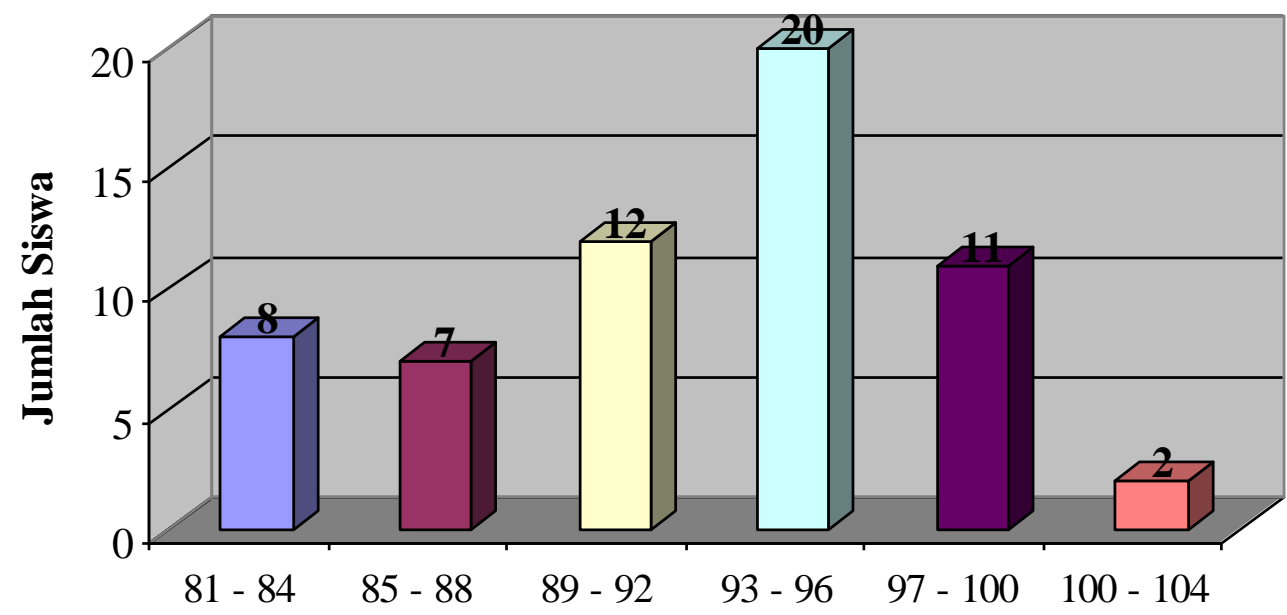

\section{Interval Skor}

\section{Gambar 3. Histogram Data Posttest}

Setelah data dinyatakan berdistribusi normal dan homogen, maka selanjutnya dilakukan uji hipotesis dengan menggunakan uji-t.

Harga $M d$ dan $\mathrm{X}^{2} \mathrm{~d}$ pada tabel di atas diperoleh, seperti pada hitungan berikut.

$$
\mathrm{Md}=\frac{\sum \mathrm{d}}{\mathrm{N}}
$$




$$
\mathrm{Md}=\frac{670}{60}=11,17
$$

Setelah diperoleh selisih (Md) data pretest dan data posttest, maka langkah selanjutnya dilakukan perhitungan varians $\left(\sum X^{2} d\right)$ menggunakan rumus sebagai berikut.

$$
\begin{aligned}
& \sum \mathrm{X}^{2} \mathrm{~d}=\sum \mathrm{d}^{2}-\frac{\left(\sum \mathrm{d}\right)^{2}}{\mathrm{~N}} \\
& \sum \mathrm{X}^{2} \mathrm{~d}=7532-\frac{(670)^{2}}{60} \\
& \sum \mathrm{X}^{2} \mathrm{~d}=50,33
\end{aligned}
$$

Harga Md dan $\sum \mathrm{X}^{2} \mathrm{~d}$ yang diperoleh disubsitusikan ke dalam rumus uji t sebagai berikut.

$$
\begin{aligned}
& \mathrm{t}=\frac{\mathrm{Md}}{\sqrt{\frac{\sum \mathrm{X}^{2} \mathrm{~d}}{\mathrm{~N}(\mathrm{~N}-1)}}} \\
& \mathrm{t}=\frac{11,17}{\sqrt{\frac{50,33}{60(60-1)}}} \\
& \mathrm{t}=\frac{11,17}{\sqrt{\frac{50,33}{3540}}} \\
& \mathrm{t}=\frac{11,17}{\sqrt{0,845912}} \\
& \mathrm{t}=\frac{11,17}{0,919735} \\
& \mathrm{t}=12,15
\end{aligned}
$$

Menentukan harga $\mathrm{t}_{\text {tabel }}$ dapat dilihat pada distribusi $\mathrm{t}$ dengan $\mathrm{dk}=60-2=58$, sehingga diperoleh $t_{\text {tabel }}=1,67$. Dengan kriteria pengujian hipotesis, terima $\mathrm{H}_{0}$ jika $\mathrm{t}_{\text {hitung }}<\mathrm{t}_{\text {tabel}}$, dan tolak $\mathrm{H}_{0}$ untuk harga yang lain. Berdasarkan kriteria tersebut, dinyatakan bahwa $t_{\text {hitung }}=12,15>t_{\text {tabel }}=1,67$. Ini berarti Ha yang menyatakan bahwa layanan 
bimbingan klasikal berbantuan media video dapat meningkatkan motivasi belajar siswa di SMP Negeri 2 Kikim Selatan diterima kebenarannya.

\section{B. Pembahasan}

Penelitian ini dilaksanakan di SMP Negeri 2 Kikim yang berlamatkan di desa Nanjungan kecamatan Kikim Selatan. Alasan pelaksanaan penelitian ini dikarenakan motivasi belajar siswa yang kurang, hal ini disebabkan oleh beberapa faktor antara lain fasilitas belajar yang masih kurang lengkap, masih rendahnya presentase untuk melanjutkan ke sekolah yang lebih tinggi sehingga siswa tidak mempunyai motivasi untuk belajar lebih giat lagi, kurangnya kesadaran orang tua akan pentingnya pendidikan bagi anak-anaknya, lokasi sekolah yang jauh dari jalan atau lokasi yang masuk ke dalam desa sehingga menyebabkan tidak banyak siswa yang berminat sekolah di SMP Negeri 2 Kikim Selatan Kabupaten Lahat. Oleh karena itu, sebagai salah satu upaya untuk meningkatkan motivasi belajar digunakanlah layanan bimbingan klasikal berbantuan media video.

Berdasarkan hasil analisis data dinyatakan layanan bimbingan klasikal berbantuan media video dapat meningkatkan motivasi belajar siswa di SMP Negeri 2 Kikim Selatan. Adanya pengaruh tersebut menurut Munir (2012: 348) dikarenakan media video merupakan teknologi penangkapan, perekaman, pengolahan, dan penyimpanan, pemindahan, dan perekonstruksian urutan gambar diam dengan menyajikan adeganadegan dalam gerak secara elektronik. Video menyediakan sumberdaya yang kaya dan hidup bagi aplikasi multimedia. Dengan media tersebut, tentunya dapat menimbulkan dorongan bagi siswa untuk meningkatkan aktivitas belajarnya.

Temuan penelitian ini juga sejalan hasil studi Asmarita (2019), bahwa bimbingan klasikal dapat meningkatkan motivasi belajar siswa. Demikian juga penelitian Janare Putra (2017) bahwa media layanan bimbingan melalui media dapat meningkatkan motivasi belajar siswa. 


\section{KESIMPULAN}

Hasil penelitian yang telah dilakukan dapat ditarik suatu kesimpulan bahwa layanan bimbingan klasikal berbantuan media video dapat meningkatkan motivasi belajar siswa di SMP Negeri 2 Kikim Selatan. Hal ini dibuktikan dari hasil pengujian hipotesis dimana $t_{\text {hitung }}=12,15>t_{\text {tabel }}=1,67$ yang berarti tolak $H_{0}$ dan terima $H_{a}$.

\section{DAFTAR PUSTAKA}

Amiludin, Sugiman. 2016. Pengaruh Problem Posing dan PBL Terhadap Prestasi Belajar dan Motivasi Belajar Mahasiswa Pendidikan Matematika. Jurnal Riset Pendidikan Matematika. Volume 3, No 1, Mei 2016, ISSN: 23562684, Online ISSN: 2477-1503.

Arikunto, Suharsimi. 2010. Prosedur Peneltian, Edisi Revisi 2010. Jakarta: Rineka Cipta.

Budiman, Arif. 2017. Keefektifan Bimbingan Blasikal Berbantuan Media Audio Visual Terhadap Pernikahan Usia Dini. Jurnal Penelitian Pendidikan Indonesia. Vol. 2, No. 2, Hal, 1, April 2017, ISSN: 2477- $2240 \quad$ (Media Cetak). 2477-3921 (Media Online).

Chang T, C. 2013. The Study On Motivation And Anxiety Of English Learning Of Students At A Taiwan Technical University. International Journal of English Language Teaching. Volume 1, No 1, September 2013.

Direktorat Jendral Guru dan Tenaga Kementrian Kependidikan dan Kebudayaan. 2016. Panduan Operasional Penyelenggaraan Bimbingan dan Konseling Sekolah Menengah Pertama. Jakarta.

Djamarah, Zain. 2010.Strategi Belajar Mengajar. Edisi Revisi 2010. Jakarta: Rineka Cipta.

Fadhli, M. 2015. Pengembangan media Pembelajaran Berbasis Video di Kelas $\quad I V$ Sekolah Dasar. Jurnal Dimensi Pendidikan dan Pembelajaran, Volume 3, No. 1 Januari 2015.

Ferdiansyah, M. 2015. Dasar Penelitian Kualitatif. Bogor: Herya Media.

Hamdani. , 2011. Strategi Belajar Mengajar. Bandung: Pustaka Setia.

Hamdu, Lisa. 2011. Pengaruh Motivasi belajar Siswa Terhadap Prestasi Belajar IPA di Sekolah Dasar. Jurnal Penelitian Pendidikan. Volume $\quad 12$, No 1, April 2011, ISSN: 1412-565X.

Kiswoyowati. 2011. Pengaruh Motivasi Belajar dan Kegiatan Belajar Siswa Terhadap Kecakapan Hidup Siswa. Jurnal Pendidikan Teknologi dan Kejuruan SPS. Edisi Khusus, No 1, Agustus 2011, ISSN: 1412-565X. 
Mukhtar, Yusuf, dan Budiamin. 2016. Program Layanan Bimbingan Klasikal untuk Meningkatkan Self-Control Siswa. Jurnal Bimbingan dan Konseling. Volume 5, No 1, 2016, ISSN: 2301-6167, 2528-7206 (online).

Munir. 2012. Multimedia Konsep dan Aplikasi dalam Pendidikan. Bandung: Alfabeta.

Sudjana. 2005. Metode Statistika. Bandung: Angkasa.

Sugiyono. 2018. Metode penelitian Manajemen. Bandung: Alfabeta.

Suprihatin. 2015. Upaya Guru Dalam Meningkatkan Motivasi Belajar Siswa. Jurnal Pendidikan Ekonomi. Volume 3, No 1, 2015, ISSN: 2442-9449. 